\title{
Knowledge and Practices on i-Ta'aleem and other Educational Technologies among International Islamic University Malaysia Kulliyyah of Medicine Lecturers
}

Nora Binti Mat Zin ${ }^{1}$, Karimah Hanim Abd Aziz ${ }^{1}$, Yahia F Husin AlHadeethi ${ }^{1}$, Muhammad Rasydan Abd Ghani ${ }^{1}$

${ }^{1}$ Medical Education Unit, Kulliyyah of Medicine, International Islamic University Malaysia

Presenter: Nora Mat Zin

Introduction: Technologies in the classroom require teacher's knowledge and skills in utilizing it. Teaching for medical student can be different in some areas. To date, no studies has been conducted on the use of technologies among medical lecturer in International Islamic University Malaysia (IIUM). Thus, the objective of this survey is to determine the level of awareness, practice and perception of learning management system ( $\mathrm{i}$-Ta'aleem) and educational technologies among Kulliyyah of Medicine (KOM) lectures. Materials and Methods: This cross-sectional study was conducted among all IIUM KOM lecturers. Only $26.1 \%$ responded to the self-administered questionnaire which was distributed via google form for one month. Descriptive analysis was used to analyze the background information and their awareness, practice and perception. Results: Majority of the respondents were male $(56.8 \%)$, permanent staff $(94.6 \%)$ with mean years of service at IIUM was 6.7. Most of them owned technology tools [smartphone $(100 \%)$, personal computer (73.0\%), tablet (54.1\%) and laptop (97.3\%)]. All of them heard about i-Ta'aleem. However, $78.4 \%$ never use i-Ta'aleem and only a small percentage of them always uses other technologies for their teaching and learning $(2.7 \%$ to $5.4 \%)$ except the usage of laptop (48.6\%) and projector (59.5\%). Conclusion: Although the lecturers were aware about i-Ta'aleem and owned high technology tools and gadget, only a small percentage of them use it in teaching activities. 